\title{
A novel mono-carbonyl analogue of curcumin induces apoptosis in ovarian carcinoma cells via endoplasmic reticulum stress and reactive oxygen species production
}

\author{
XIE ZHANG $^{1 *}$, HAN-QING ZHANG ${ }^{1 *}$, GUANG-HUI ZHU ${ }^{2}$, YU-HUANG WANG ${ }^{2}$, XI-CHONG YU ${ }^{1}$, \\ XIN-BO ZHU ${ }^{1}$, GUANG LIANG ${ }^{1}$, JIAN XIAO ${ }^{1}$ and XIAO-KUN LI ${ }^{1,3}$
}

${ }^{1}$ Key Laboratory of Biotechnology Pharmaceutical Engineering, School of Pharmaceutical Science, Wenzhou Medical College, Wenzhou 325035; ${ }^{2}$ The Second Affiliated Hospital, Wenzhou Medical College, Wenzhou 325000; ${ }^{3}$ Ministry of Education Bioreactor and Drug Development Research Center, Jilin Agricultural University, Changchun 130118, P.R. China

Received August 30, 2011; Accepted November 2, 2011

DOI: $10.3892 / \mathrm{mmr} .2011 .700$

\begin{abstract}
The aim of the present study was to investigate the apoptosis of human ovarian cancer cell lines, A2780 and CP70, induced by a novel curcumin analogue, B19. The proliferation of cells was detected with methyl thiazolyl tetrazolium (MTT) assay and apoptosis was examined by flow cytometry. Reactive oxygen species (ROS) were assessed by the fluorescent indicator DCF-DA. The protein expression of the endoplasmic reticulum (ER) stress pathways, GRP78, XBP-1, ATF-4 and CHOP, was examined with Western blotting. A growth inhibitory effect was observed after treatment with B19 in a dose-dependent manner and with more potential than curcumin. At $20 \mu \mathrm{M}$, B19 induced significant apoptosis in CP70 cells. Furthermore, B19 induced the ER stress response, while curcumin had no effect on ER stress. These results suggest that B19 has more effective antitumor properties than curcumin, and is associated with the activation of ER stress and ROS in ovarian cancer cells.
\end{abstract}

\section{Introduction}

Ovarian cancer has been, and remains, one of the most fatal gynecological malignancies worldwide for the past 20 years. (1). Treatment of ovarian cancer typically involves surgery and chemotherapy. Unfortunately, the outcome of chemotherapy and surgery is poor. The 5 -year survival rate for women with advanced epithelial ovarian carcinoma is only $30 \%$ (2). Since the chances of developing resistance to chemotherapy are high, many ovarian carcinoma patients

Correspondence to: Dr Jian Xiao, Key Laboratory of Biotechnology Pharmaceutical Engineering, School of Pharmaceutical Science, Wenzhou Medical College, Wenzhou, Zhejiang 325035, P.R. China E-mail: xfxj2000@126.com

"Contributed equally

Key words: curcumin analogues, ovarian cancer, reactive oxygen species, endoplasmic reticulum stress are not responsive to current drugs. Therefore, the development of novel therapies for the treatment of ovarian cancer is particularly urgent. The development of such a therapy is the long-term objective of the present study.

Curcumin, a well-known constituent of traditional medicine, has been used to treat several different types of cancer in clinical trials, including ovarian cancer (3). However, numerous studies indicate that its poor bioavailability and pharmacokinetic profiles have limited its application in anticancer therapies (4-6). The chemical modification of curcumin is an effective way to obtain potential analogues with better bioavailability and antitumor activities (7-12). In previous studies, we designed and synthesized a series of mono-carbonyl analogues of curcumin with more stability and better pharmacokinetic profiles. We also demonstrated that some of the analogues exhibited better antitumor activity compared to curcumin (13-16).

The molecular mechanism of curcumin is still being investigated. Reactive oxygen species (ROS) are considered to be one of the mechanisms for the induction of apoptosis by curcumin in cancer cells (17-19). ROS have been proven to perform certain functions, such as inflicting damage to lipids, proteins and DNA in early apoptosis (20). Furthermore, ROS induce the depolarization of the mitochondrial membrane and cause mitochondrial dysfunction (19). Therefore, the role of ROS in the cytotoxic mechanisms associated with B19 was investigated in the present study.

More recently, endoplasmic reticulum (ER) stress was established as another mechanism resulting in cancer cell apoptosis by curcumin. It has been demonstrated that treatment with curcumin causes ER stress-related apoptosis of cancer cell lines, including human leukemia HL-60, murine melanoma B16-F10 and non-human lung cancer A549 cells (20-23). ER stress induces the unfolded protein response (UPR), an intracellular signaling pathway, which regulates the accumulation of unfolded or misfolded proteins in the ER and plays an important role in regulating cell growth, differentiation and apoptosis (24-26). However, it has not been clarified whether ER stress plays a role in curcumin or curcumin analogue-induced apoptosis in ovarian adenocarcinoma cell lines. 
In the present study, we synthesized a new curcumin analogue, (1E, 4E)-1, 5-bis (2-methoxyphenyl) penta-1, 4-dien3-one (B19), and compared the effects of B19 and curcumin in pre-clinical model systems using ovarian adenocarcinoma cell lines (A2780/CP70) on cell growth and apoptosis. We concluded that B19 induced A2780/CP70 apoptosis through the same pathways as curcumin, through ROS and ER stress. We demonstrated that B19, as a new curcumin analogue, is more active than curcumin in the inhibition of ovarian cancer cell proliferation and induction of apoptosis. Consequently, the synthetic derivative of curcumin B19 has potential as a new therapeutic agent for ovarian cancer.

\section{Materials and methods}

Synthesis of B19 (Fig. 1). The general procedure of synthesis of B19 is described as follows (15): an amount of $7.5 \mathrm{mmol}$ acetone was added to a solution of $15 \mathrm{mmol}$ arylaldehyde in $\mathrm{MeOH}(10 \mathrm{ml})$. The solution was stirred at room temperature for $20 \mathrm{~min}$, followed by dropwise addition of $\mathrm{NaOCH}_{3} /$ $\mathrm{CH}_{3} \mathrm{OH}(1.5 \mathrm{ml}, 7.5 \mathrm{mmol})$. The mixture was stirred at room temperature and monitored with TLC. When the reaction was completed, the residue was poured into a saturated $\mathrm{NH}_{4} \mathrm{Cl}$ solution and filtered. The precipitate was washed with water and cold ethanol, and dried in a vacuum. The solid was purified by chromatography over silica gel using $\mathrm{CH}_{2} \mathrm{Cl}_{2} / \mathrm{CH}_{3} \mathrm{OH}$ as the eluent to yield the compounds.

Treatment of ovarian cancer cells with B19 and curcumin. Human ovarian cancer cell lines (A2780 and CP70) obtained from the American Type Culture Collection were grown in RPMI-1640 medium, containing 10\% FBS in a humidified environment at $37^{\circ} \mathrm{C}$ with $5 \% \mathrm{CO}_{2}$. $\mathrm{B} 19$ and curcumin were soluted in DMSO. The cells were treated with various concentrations of B19 and curcumin $(5,10$ and $20 \mu \mathrm{M})$ for $24 \mathrm{~h}$. Control cultures were treated with DMSO and were processed similarly.

MTT assay. A2780 and CP70 cells were grown in a 96-well plate for $24 \mathrm{~h}$ and then treated with different doses of B19 and/ or curcumin $(5,10$ and $20 \mu \mathrm{M})$ for $24 \mathrm{~h}$, followed by MTT treatment $(5 \mathrm{mg} / \mathrm{ml})$ in each well for $4 \mathrm{~h}$ at $37^{\circ} \mathrm{C}$, as previously described (27). MTT was aspirated and $100 \mu \mathrm{l}$ of DMSO was added to each well. Absorbance at $570 \mathrm{~nm}$ was read in a plate reader. Each treatment was carried out in triplicate. The mean of three values was determined and the results are expressed as the percentage of the control.

Analysis of the rate of apoptosis. CP70 cells were grown for $24 \mathrm{~h}$ in a 6-mm plate and then treated with varying doses of $\mathrm{B} 19$ or curcumin $(5,10$ and $20 \mu \mathrm{M})$ for $24 \mathrm{~h}$. Cells were washed with PBS three times, then digested by $0.25 \%$ tryptan-EDTA. After centrifugation, cells were resuspended in $0.5 \mathrm{ml}$ PBS. Cells were then stained with Annexin V and propidium iodide 5 in the presence of $100 \mathrm{mg} / \mathrm{ml}$ RNAse and $0.1 \%$ Triton X-100 for $30 \mathrm{~min}$ at $37^{\circ} \mathrm{C}$. Flow cytometric analysis was performed using a fluorescence-activated cell sorter.

Caspase- 3 assay. Caspase- 3 activity was determined using a colorimetric assay (ApoAlert; Clontech, Heidelberg, Germany)
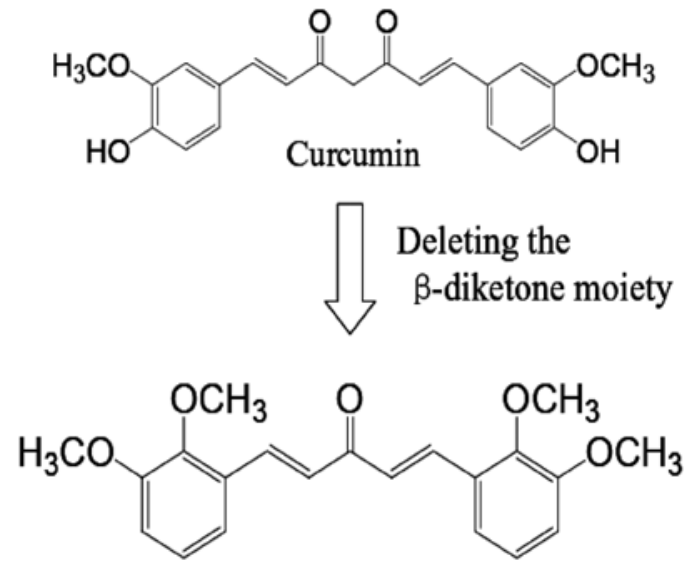

Figure 1. Schematic presentation of the synthesis of B19.

according to the manufacturer's protocol. In this assay, the capacity of cellular caspase-3 to cleave the labeled substrate DEVD-p-nitroaniline (DEVD-pNA) was measured spectrophotometrically. In brief, apoptosis was induced by incubation with $0.4 \mathrm{mM} \mathrm{H}_{2} \mathrm{O}_{2}$ for $24 \mathrm{~h}$, as previously described (28). The CP70 cells were then harvested, and aliquots of $2.5 \times 10^{6}$ cells were used for each reaction. Cell lysates were incubated in the presence or absence of $5 \mu \mathrm{l}$ caspase-3-substrate (DEVD-pNA) for $1 \mathrm{~h}$ at $37^{\circ} \mathrm{C}$. Absorbance was measured at $405 \mathrm{~nm}$ in a microplate reader. Un-induced and induced cells without substrate served as the background control. Induced cells were incubated with DEVD-CHO, an inhibitor of caspase-3 as a negative control.

ROS analysis. Dichlorodihydrofluorescein diacetate (DCFDA) is a cell-permeant indicator for ROS. The fluorescence of this cell-permeable agent significantly increases after oxidation. CP70 cells were incubated with B19 or curcumin for $30 \mathrm{~min}$. Hydrogen dioxide $\left(\mathrm{H}_{2} \mathrm{O}_{2}, 300 \mu \mathrm{M}\right)$ was added as a positive control for $10 \mathrm{~min}$. Following treatment, the medium was changed and loaded with $10 \mu \mathrm{M}$ DCF-DA in serum-free DMEM media for $30 \mathrm{~min}$ at $37^{\circ} \mathrm{C}$. Cells were scraped with PBS and centrifuged at 5,000 rpm for $5 \mathrm{~min}$. Lysis buffer, $0.5 \mathrm{ml},(0.1 \mathrm{~N} \mathrm{NaOH}$ in $50 \% \mathrm{MeOH})$ was added to the cell pellets, then vortexed and centrifuged at 5,000 rpm for $5 \mathrm{~min}$. Fluorescence of $200 \mu \mathrm{l}$ supernatant was read with a 485and 520-nm excitation beam. The fluorescence values were normalized to protein levels in each sample, and the results are expressed as the percentage of change in fluorescence per milligram of protein, and compared to the vehicle controls.

Western blotting. GRP78, CHOP, XBP-1 and ATF-4 expression levels were examined by Western blotting. Briefly, A2780 and CP70 cells were lysed, supernatants were collected and proteins were resolved on Tris- $\mathrm{HCl}$ polyacrylamide gels at $120 \mathrm{~V}$. The proteins were transferred to a polyvinylidene difluoride (PVDF) blotting membrane, and the membranes were probed with rabbit polyclonal antibody. Details of the secondary antibodies used and their detection by chemiluminescence were previously described (27). Equal loading was verified by determining the protein concentration with the Bio-Rad protein assay (Bio-Rad, Hercules, CA, USA) and using the same amount of protein from protein lysates for 
A

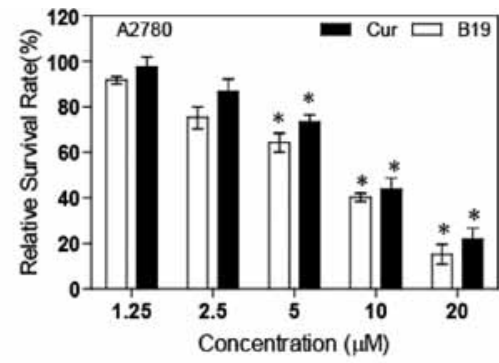

B

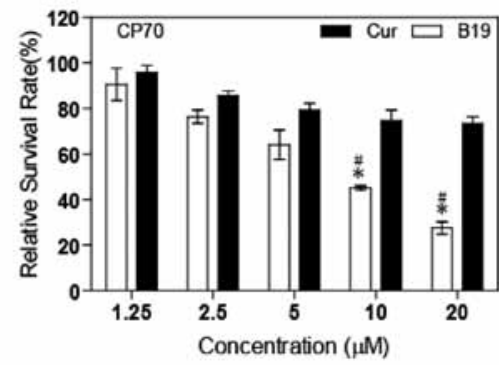

C
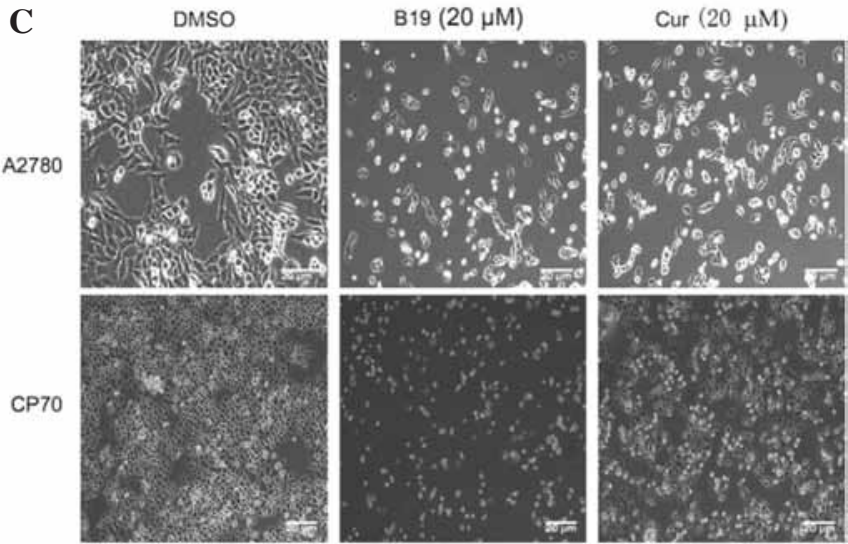

Figure 2. Effects of B19 and curcumin (Cur) on cell growth of (A) A2780 and (B) CP70 cells as determined by MTT assay. The percentage of the control was quantitated from three independent experiments performed in triplicate. The mean of three values was determined, and the results are expressed as the percentage of the control. Data are presented as the means \pm SD. "Statistically significant $(\mathrm{P}<0.5$, t-test) as compared to DMSO control.

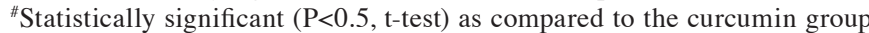
at the same concentration. (C) Effects of B19 and curcumin on cell morphological changes.

electrophoretic analysis. $\beta$-actin was used as the standard, and the ratio between the analyzed protein and $\beta$-actin from the quantitative densitometric analysis was used for comparison of the control and experimental samples.

Statistical evaluation. All assays were performed at least three times, and levels of all parameters measured are expressed as the means \pm standard deviation (SD). Statistical comparisons between cells treated with B19 and curcumin vs. the control were based on the t-test. $\mathrm{P}<0.05$ was considered to denote statistical significance.

\section{Results}

B19 inhibition of cancer cell viability more potent than curcumin. In this study, we examined the effects of B19 and curcumin on cell proliferation in the ovarian cancer cell line A2780 and its cisplatin-resistant variant CP70. After $24 \mathrm{~h}$ of
A
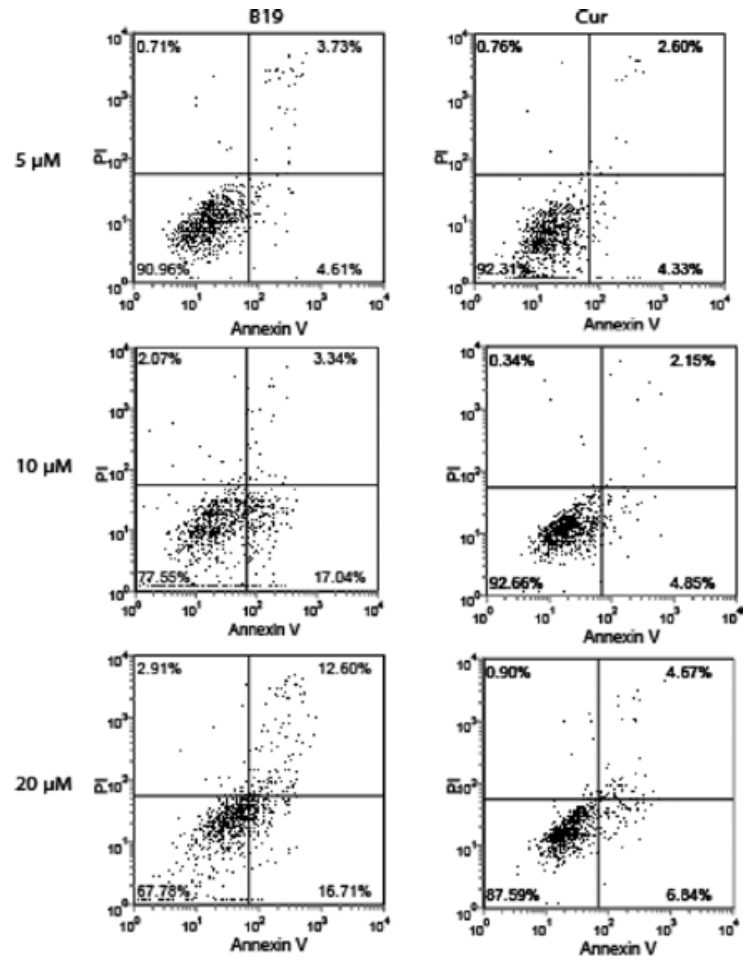

$\mathbf{B}$

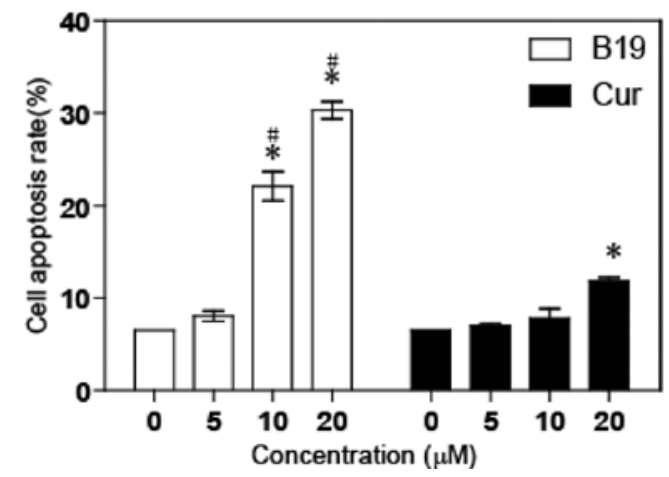

Figure 3. Effects of B19 and curcumin (Cur) on the induction of apoptosis in CP70 cells as determined by flow cytometry. (A) CP70 cells were treated with various amounts of $\mathrm{B} 19(5,10$ and $20 \mu \mathrm{M})$ or curcumin $(5,10$ and $20 \mu \mathrm{M})$ for $24 \mathrm{~h}$, then stained with Annexin V-FITC/propidium iodide and detected by flow cytometry. (B) Histogram illustrating the rate of cell apoptosis from three FACS analysis from three separate treatments. "Statistically significant $(\mathrm{P}<0.5$, t-test) as compared to DMSO control. "Statistically significant $(\mathrm{P}<0.5$, t-test $)$ as compared to the curcumin group at the same concentration.

treatment, both B19 and curcumin exhibited greater levels of growth inhibition in A2780 cells (Fig. 2A). Only B19 significantly suppressed cell proliferation in CP70 cells in a dose-dependent manner within the 24-h treatment. By contrast, curcumin treatment, even at $20 \mu \mathrm{M}$, resulted in only $73 \%$ cell viability after $24 \mathrm{~h}$ (Fig. 2B). The results demonstrated that B19 is more potent than curcumin in the growth suppression of cisplatin-resistant ovarian cancer cell lines, but not cisplatinsensitive cancer cell lines.

B19 is more effective than curcumin in inducing apoptosis in CP70 cells. At a sufficiently high dose, curcumin has been shown to induce apoptosis in many cancer cells, including ovarian cancer. We detected the effects of B19 and curcumin on the induction of apoptosis on CP70 cells by flow cytometry. The results (Fig. 3A) demonstrated that B19 dose-dependently 
A

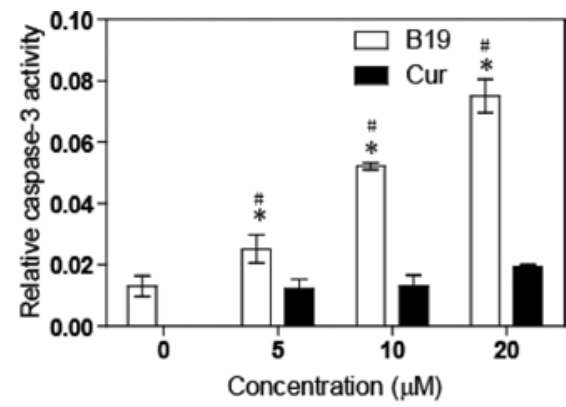

B

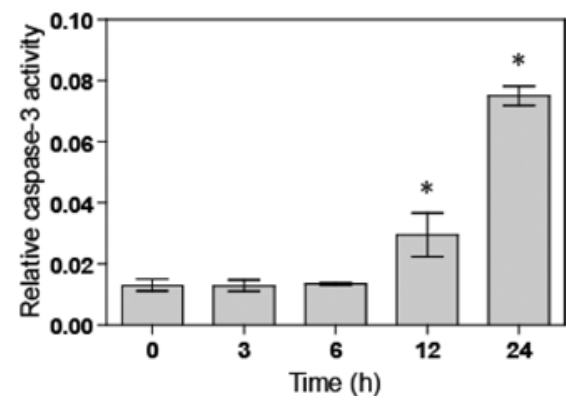

Figure 4. B19 and curcumin (Cur) induces the activity of caspase-3 in CP70 cells. (A) CP70 cells were treated with B19 $(5,10$ and $20 \mu \mathrm{M})$ or curcumin $(5,10$ and $20 \mu \mathrm{M})$ for $24 \mathrm{~h}$, before caspase-3 activity was determination as described in Materials and methods. (B) CP70 cells were treated with B19 $(20 \mu \mathrm{M})$ or curcumin $(20 \mu \mathrm{M})$ for various time periods. Data represent the means $\pm \mathrm{SD}$ of three experiments. "Statistically significant $(\mathrm{P}<0.5$, t-test $)$ as compared to DMSO control. "Statistically significant $(\mathrm{P}<0.5$, t-test) as compared to the curcumin group at the same concentration.

increased cell apoptosis rates after $24 \mathrm{~h}$ of treatment. B19 at $20 \mu \mathrm{M}$ significantly induced apoptosis in CP70 cells $(29.31 \%)$, compared to curcumin (11.5\%; Fig. 3B). Caspase-3 is a key effector molecule in the apoptosis pathway involved in amplifying the signal from initiator caspases, such as caspase- 8 and caspase-12. Caspase-3 activity was determined by a colorimetric assay according to the manufacturer's protocol. An increased activation of caspase- 3 was observed within $24 \mathrm{~h}$ in the CP70 cells treated with $20 \mu \mathrm{M}$ B19, however, curcumin did not induce caspase-3 activation (Fig. 4A). B19 also exhibited an increase in caspase-3 activity in a time-dependent manner (Fig. 4B). These data suggest that B19 is a potent inducer of apoptosis, even at low doses, whereas no such effect was observed with curcumin in cisplatin-resistant ovarian cells.

B19 and curcumin induces the production of ROS in CP70 cells. ROS have been shown to be involved in cell apoptosis induced by anticancer drugs. To measure the capacity of B19 and curcumin to cause intracellular oxidation, a specific oxidation-sensitive fluorescent dye DCFH-DA was used. DCFH-DA-derived fluorescence was determined in CP70 cells treated with 5, 10 and $20 \mu \mathrm{M}$ B19 or curcumin for $1 \mathrm{~h}$. Compared to the no treatment control group, both B19 and curcumin increased stained cells for ROS. The levels of ROS were higher after B19 treatment than with curcumin at all concentrations. At $20 \mu \mathrm{M}, \mathrm{B} 19$ increased ROS levels 3-fold more than curcumin (Fig. 5). These results demonstrated that $\mathrm{B} 19$ is more effective than curcumin in promoting ROS production.

B19 activates ER stress pathway. A novel pathway of cell apoptosis via ER stress was recently reported (29). Inductions

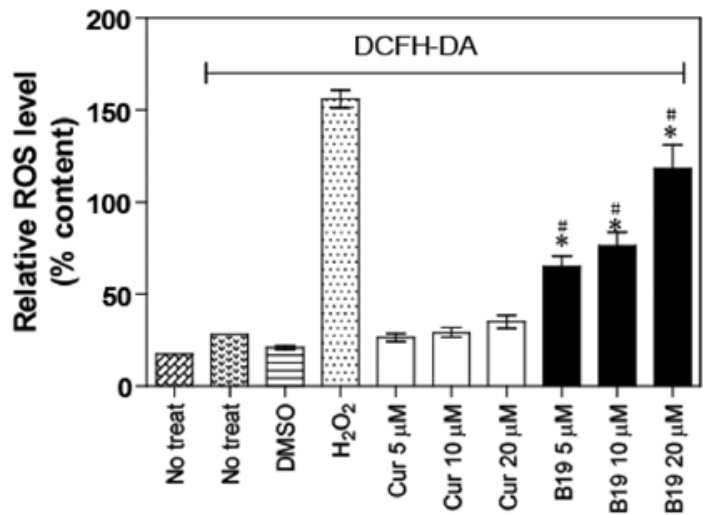

Figure 5. Role of B19 and curcumin-induced ROS generation in CP70 cells. Assessment of ROS generation in CP70 cells treated with different concentrations of $\mathrm{B} 19(5,10$ and $20 \mu \mathrm{M})$ and curcumin (Cur) (5, 10 and $20 \mu \mathrm{M})$, as described in Materials and methods.

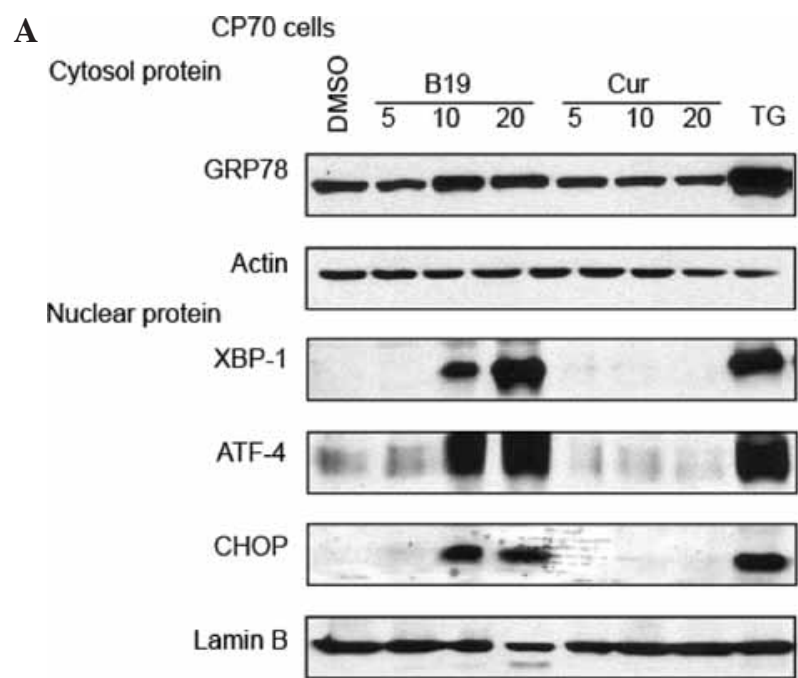

B A2780 cells

Nuclear protein

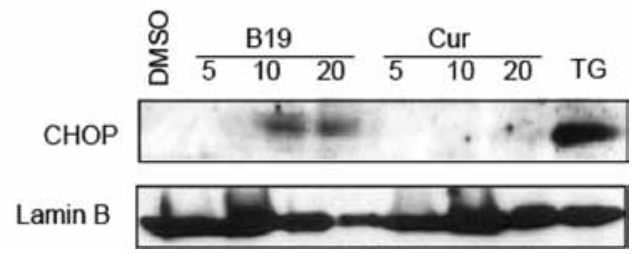

Figure 6. Concentration-dependent activation of the ER stress pathway in (A) CP70 and (B) A2780 cells. Representative immunoblots against GRP78 from cytosol extracts, CHOP, ATF-4, XBP-1 from nuclear extracts treated with $\mathrm{B} 19$ or curcumin $(5,10$ and $20 \mu \mathrm{M})$ for $24 \mathrm{~h}$. Actin and Lamin B were used as a loading control; TG treatment was used as positive control of ER stress.

of the downstream transcription factors, XBP-1, ATF-4 and CHOP, are markers for the activation of the UPR. In this study, we compared the effects of B19 and curcumin on the UPR activation in CP70 cells. The results indicated that even though B19 and curcumin inhibited CP70 cell growth, only B19 induced the ER stress response in both A2780 and CP70 cells. As illustrated in Fig. 6A, B19 significantly induced the expression of CHOP, ATF-4 and XBP-1 in a dose-dependent 
manner in CP70 cells. Curcumin, on the other hand, had no effect on the cells, even at the $20 \mu \mathrm{M}$ concentration. Notably, we found that, albeit slightly, B19 induced the CHOP expression in A2780 cells (Fig. 6B). Curcumin had no effect at 5 to $20 \mu \mathrm{M}$. These results suggest that B19-induced UPR activation may represent a major cellular mechanism of its anticancer activity in CP70 and A2780 cells.

\section{Discussion}

Ovarian cancer is one of the most common fatal gynecological types of cancer in women. Several studies have presented the protective properties of curcumin against ovarian cancer. Curcumin has also been shown to activate multiple pathways, including ER stress and UPR pathways, albeit at high concentrations. This study suggests that curcumin may be an ideal agent to target the oncogenic pathway in ovarian cancer. Curcumin has been found to be safe in clinical trials. Doselimiting toxicity was not observed in many studies. However, since curcumin is poorly absorbed through the gut, more potent and soluble curcumin analogues have been developed (4).

Synthetic chemical analogues to molecularly target chemotherapeutic drugs are a common technique used in developing new drugs. These events include the acquisition of self-sufficient growth signals, insensitivity to signals that typically inhibit proliferation, the use of the survival pathway to evade apoptosis and the initiation of angiogenesis to ensure sufficient oxygen. There are several curcumin analogues that have already been reported, including dimethoxycurcumin and EF-24 $(17,27,28)$. In our previous study, a series of monocarbonyl analogues of curcumin were designed by deleting the highly reactive $\beta$-diketone moiety in the structure of curcumin, considered to be responsible for the in vitro instability and the in vivo pharmacokinetic disadvantages.

Cisplatin is one of the most commonly prescribed anticancer drugs for ovarian cancer patients. In this study, we identified agents that are significantly more active in vitro against ovarian cancer cell resistance to cisplatin (CP70) than against the parent non-resistant cells (A2780). We demonstrated that B19 was more potent than curcumin in the inhibition of cell viability in the cisplatin-resistant cell line CP70. In the cisplatin-sensitive cell line A2780, B19 and curcumin had no significant effect on their inhibitory activity.

In the present study, it was also found that B19 induced apoptosis in CP70 cells. B19 is more efficacious than curcumin in the induction of caspase-3. The evidence of apoptosis in CP70 cells was investigated. Two different pathways, the death receptor pathway and the mitochondrial pathway, play major roles in regulating apoptosis in cancer cells. The caspase family includes critical mediators of apoptosis. The death receptor pathway and the mitochondrial pathway initially begin with the activation of caspase- 8 and caspase- 9 , respectively. Furthermore, both activated caspase- 8 and caspase- 9 were found to activate caspase-3 and induce apoptosis. Caspase-3 was activated in a dose- and time-dependent manner in CP70 cells treated with B19. Curcumin was found to have no significant effect. This suggests that B19 may induce apoptosis via a pathway mediated by a caspase-dependent signaling pathway.

At apoptosis-inducing concentrations, B19 induced ROS formation within $30 \mathrm{~min}$ of treatment. ROS included free radicals, such as superoxide, hydroxyl radical and non-radical derivatives of oxygen. The free radical generation induced progression of cell apoptosis, or death, including damaging cellular DNA, proteins and lipid membranes. Thus, our data support the fact that oxidative stress plays a role as a common mediator of B19-induced apoptosis.

A previous study found that the intracellular organelles, including the ER, promote cell apoptosis signal. The UPR is an intracellular signaling pathway which regulates the accumulation of unfolded or misfolded proteins in the ER and plays an important role in regulating cell growth, differentiation and apoptosis (24-26). Therefore, the possibility that B19 induces apoptosis via ER stress was examined. CHOP is a typical ER stress-regulated protein involved in ER stress-induced apoptosis. Our results on CHOP induction by B19 in CP70 cells suggest that B19 may trigger ER stress. B19 was also found to increase the levels of XBP-1, ATF-4 and GRP78, all of which are additional proteins increased during ER stress. However, curcumin, at the same concentration, had no effect on CHOP, ATF-4 and XBP-1, suggesting that curcumin inhibited ovarian cancer growth and is not involved in ER stress. Notably, in A2780 cells, although the cell inhibiting rate is not significantly different between B19 and the curcumintreated group, the Western blotting results illustrated that B19 activates CHOP at 10 and $20 \mu \mathrm{M}$. Curcumin had no effect on the CHOP expression, which suggests that curcumin induces A2780 cell apoptosis or death, and is not involved in the ER stress pathway.

In conclusion, our studies first demonstrated a novel monocarbonyl analogue of curcumin B19. Treatment of ovarian cancer cells with B19 resulted in cell growth inhibition in vitro. Similar to curcumin, B19 also had multiple molecular targets, including ROS and ER stress. The enhanced potency in ovarian cancer and better pharmacokinetic profiles renders it a strong candidate for therapeutic applications in ovarian cancer, as well as other types of cancer.

\section{Acknowledgements}

This study was supported by the National Natural Science Funding of China (30901819), the Science Foundation of Zhejiang Province of China (Y2090668, Y2110522), the Zhejiang Medical Science Technology Project (2011KYB049) and the Science and Technology Grant of Wenzhou City (Y20090175).

\section{References}

1. Singh AP, Senapati S, Ponnusamy MP, Jain M, Lele SM, Davis JS, Remmenga S and Batra SK: Clinical potential of mucins in diagnosis, prognosis, and therapy of ovarian cancer. Lancet Oncol 11: 1076-1085, 2008.

2. McGuire WP, Hoskins WJ, Brady MF, Kucera PR, Partridge EE, Look KY, Clarke-Pearson DL and Davidson M: Cyclophosphamide and cisplatin compared with paclitaxel and cisplatin in patients with stage III and stage IV ovarian cancer. N Engl J Med 334: 1-6, 1996.

3. Hatcher H, Planalp R, Cho J, Torti FM and Torti SV: Curcumin: from ancient medicine to current clinical trials. Cell Mol Life Sci 65: 1631-1652, 2008

4. Anand P, Kunnumakkara AB, Newman RA and Aggarwal BB: Bioavailability of curcumin: problems and promises. Mol Pharm 4: 807-818, 2007. 
5. Appiah-Opong R, de Esch I, Commandeur JN, Andarini M and Vermeulen NP: Structure-activity relationships for the inhibition of recombinant human cytochromes P450 by curcumin analogues. Eur J Med Chem 43: 1621-1631, 2008.

6. Sharma RA, Steward WP and Gescher AJ: Pharmacokinetics and pharmacodynamics of curcumin. Adv Exp Med Biol 595: 453-470, 2007.

7. Wang X, Lin J, Chen Y, Zhong W, Zhao G, Liu H, Li S, Wang L and Li S: Novel fatty acid synthase (FAS) inhibitors: design, synthesis, biological evaluation, and molecular docking studies. Bioorg Med Chem 17: 1898-1904, 2009.

8. Subramaniam D, May R, Sureban SM, Lee KB, George R, Kuppusamy P, Ramanujam RP, Hideg K, Dieckgraefe BK. Houchen CW and Anant S: Diphenyl difluoroketone: a curcumin derivative with potent in vivo anticancer activity. Cancer Res 68 1962-1969, 2008.

9. Selvam C, Jachak SM, Thilagavathi R and Chakraborti AK: Design, synthesis, biological evaluation and molecular docking of curcumin analogues as antioxidant, cyclooxygenase inhibitory and anti-inflammatory agents. Bioorg Med Chem Lett 15: 1793-1797, 2005

10. Ohori H, Yamakoshi H, Tomizawa M, Shibuya M, Kakudo Y, Takahashi A, Takahashi S, Kato S, Suzuki T, Ishioka C, Iwabuchi $\mathrm{Y}$ and Shibata H: Synthesis and biological analysis of new curcumin analogues bearing an enhanced potential for the medicinal treatment of cancer. Mol Cancer Ther 5: 2563-2571, 2006.

11. Mosley CA, Liotta DC and Snyder JP: Highly active anticancer curcumin analogues. Adv Exp Med Biol 595: 77-103, 2007.

12. Liang G, Li X, Chen L, Yang S, Wu X, Studer E, Gurley E, Hylemon PB, Ye F, Li Y and Zhou H: Synthesis and anti-inflammatory activities of mono-carbonyl analogues of curcumin. Bioorg Med Chem Lett 18: 1525-1529, 2008

13. Liang G, Yang SL, Shao LL, Zhao CG, Xiao J, Lv YX, Yang J, Zhao Y and Li XK: Synthesis, structure, and bioevaluation of 2,5-bis(arylmethenyl)cyclopentanones. J Asian Nat Prod Res 10 957-965, 2008

14. Liang G, Yang S, Zhou H, Shao L, Huang K, Xiao J, Huang Z and Li X: Synthesis, crystal structure and anti-inflammatory properties of curcumin analogues. Eur J Med Chem 44: 915-919, 2009.

15. Liang G, Yang S, Jiang L, Zhao Y, Shao L, Xiao J, Ye F, Li Y and Li X: Synthesis and anti-bacterial properties of mono-carbonyl analogues of curcumin. Chem Pharm Bull 56: 162-167, 2008

16. Liang G, Shao L, Wang Y, Zhao C, Chu Y, Xiao J, Zhao Y, Li X and Yang S: Exploration and synthesis of curcumin analogues with improved structural stability both in vitro and in vivo as cytotoxic agents. Bioorg Med Chem 17: 2623-2631, 2009.

17. Adams BK, Cai J, Armstrong J, Herold M, Lu YJ, Sun A, Snyder JP, Liotta DC, Jones DP and Shoji M: EF24, a novel synthetic curcumin analog, induces apoptosis in cancer cells via a redox-dependent mechanism. Anticancer Drugs 16: 263-275, 2005.

18. Thayyullathil F, Chathoth S, Hago A, Patel M and Galadari S: Rapid reactive oxygen species (ROS) generation induced by curcumin leads to caspase-dependent and -independent apoptosis in L929 cells. Free Radic Biol Med 45: 1403-1412, 2008.
19. Ozben T: Oxidative stress and apoptosis: impact on cancer therapy. J Pharm Sci 96: 2181-2196, 2007.

20. Xia C, Meng Q, Liu LZ, Rojanasakul Y, Wang XR and Jiang BH: Reactive oxygen species regulate angiogenesis and tumor growth through vascular endothelial growth factor. Cancer Res 67: 10823-10830, 2007.

21. Wu SH, Hang LW, Yang JS, Chen HY, Lin HY, Chiang JH, Lu CC, Yang JL, Lai TY, Ko YC and Chung JG: Curcumin induces apoptosis in human non-small cell lung cancer NCI-H460 cells through ER stress and caspase cascade- and mitochondriadependent pathways. Anticancer Res 30: 2125-2133, 2010.

22. Lin SS, Huang HP, Yang JS, Wu JY, Hsia TC, Lin CC, Kuo CL, Gibson Wood W and Chung JG: DNA damage and endoplasmic reticulum stress mediated curcumin-induced cell cycle arrest and apoptosis in human lung carcinoma A-549 cells through the activation caspases cascade- and mitochondrial-dependent pathway. Cancer Lett 272: 77-90, 2009.

23. Pae HO, Jeong SO, Jeong GS, Kim KM, Kim HS, Kim SA, Kim YC, Kang SD, Kim BN and Chung HT: Curcumin induces pro-apoptotic endoplasmic reticulum stress in human leukemia HL-60 cells. Biochem Biophys Res Commun 353: 1040-1045, 2007.

24. Zou W, Yue P, Khuri FR and Sun SY: Coupling of endoplasmic reticulum stress to CDDO-Me-induced up-regulation of death receptor 5 via a CHOP-dependent mechanism involving JNK activation. Cancer Res 68: 7484-7492, 2008.

25. Zhang K and Kaufman RJ: Signaling the unfolded protein response from the endoplasmic reticulum. J Biol Chem 279: 25935-25938, 2004

26. Oyadomari S and Mori M: Roles of CHOP/GADD153 in endoplasmic reticulum stress. Cell Death Differ 11: 381-389, 2004.

27. Xiao J, Chu YH. Hu KQ, Huang Y, Jiang CX, Liang G and Li XK: Synthesis and biological analysis of new curcumin analogue for enhanced potential anti-tumor activity in HepG2 cells. Oncol Rep 23: 1435-1441, 2010.

28. Pongrakhananon V, Nimmannit U, Luanpitpong S, Rojanasakul Y and Chanvorachote P: Curcumin sensitizes non-small cell lung cancer cell anoikis through reactive oxygen species-mediated Bcl-2 downregulation. Apoptosis 15: 574-585, 2010.

29. Kim I, Xu W and Reed JC: Cell death and endoplasmic reticulum stress: disease relevance and therapeutic opportunities. Nat Rev Drug Discov 7: 1013-1030, 2008.

30. Pae HO, Jeong SO, Kim HS, Kim SH, Song YS, Kim SK, Chai KY and Chung HT: Dimethoxycurcumin, a synthetic curcumin analogue with higher metabolic stability, inhibits NO production, inducible NO synthase expression and NF-kappaB activation in RAW264.7 macrophages activated with LPS. Mol Nutr Food Res 52: 1082-1091, 2008

31. Sun A, Shoji M, Lu YJ, Liotta DC and Snyder JP: Synthesis of EF24-tripeptide chloromethyl ketone: a novel curcumin-related anticancer drug delivery system. J Med Chem 49: 3153-3158, 2006. 